\title{
Erratum to: Absorptive root area and stem resistivity in whole trees of contrasting structure and size - improvement of methods
}

\author{
Jan Čermák • Nadezhda Nadezhdina • \\ Valeriy Nadezhdin • Zdeněk Staněk • Jan Koller • \\ Miroslav Trcala • Mariana Amato • Petr Kantor
}

Published online: 27 May 2015

(C) Springer International Publishing Switzerland 2015

Erratum to: Plant Soil (2014) 383:257-273

DOI 10.1007/s11104-014-2126-5

The published online paper unfortunately contained an error. The name of one of the authors Maria Amato should be corrected to Mariana Amato.

The online version of the original article can be found at http://dx. doi.org/10.1007/s11104-014-2126-5.

J. Čermák $(\bowtie) \cdot N$. Nadezhdina $\cdot$ V. Nadezhdin $\cdot$ M. Trcala $•$

P. Kantor

Faculty of Forestry and Wood Technology, Mendel Univ.

Brno, Zemědělská,

Brno 361300, Czech Republic

e-mail: cermark@mendelu.cz

\section{Z. Staněk $\cdot$ J. Koller}

Dept. of Physics, Czech Technical Univ Technická 2,

16627 Praha, Czech Republic

\section{Amato}

Dept. of Crop, Forest and Environ. Sci, Univ. of Basilicata,

Via Anteo Lucano 10, Potenza 85100, Italy 